\title{
Laser-Doping through Anodic Aluminium Oxide Layers for Silicon Solar Cells
}

\author{
Pei Hsuan Doris Lu, Alison Lennon, and Stuart Wenham \\ School of Photovoltaic and Renewable Energy Engineering, The University of New South Wales, Sydney, NSW 2052, Australia
}

Correspondence should be addressed to Pei Hsuan Doris Lu; p.lu@unsw.edu.au

Received 2 February 2015; Revised 26 June 2015; Accepted 1 July 2015

Academic Editor: Zijie Yan

Copyright (C) 2015 Pei Hsuan Doris Lu et al. This is an open access article distributed under the Creative Commons Attribution License, which permits unrestricted use, distribution, and reproduction in any medium, provided the original work is properly cited.

\begin{abstract}
This paper demonstrates that silicon can be locally doped with aluminium to form localised $\mathrm{p}^{+}$surface regions by laser-doping through anodic aluminium oxide (AAO) layers formed on the silicon surface. The resulting $\mathrm{p}^{+}$regions can extend more than $10 \mu \mathrm{m}$ into the silicon and the electrically active p-type dopant concentration exceeds $10^{20} \mathrm{~cm}^{-3}$ for the first 6-7 $\mu \mathrm{m}$ of the formed $\mathrm{p}^{+}$region. Anodic aluminium oxide layers can be doped with other impurities, such as boron and phosphorus, by anodising in electrolytes containing the extrinsic impurities in ionic form. The ions become trapped in the formed anodic oxide during anodisation, therefore enabling the impurity to be introduced into the silicon, with aluminium, during laser-doping. This codoping process can be used to create very heavily doped surface layers which can reduce contact resistance on metallisation, whilst the deeper doping achieved by the intrinsic aluminium may act to shield the surface from minority carriers. laser-doping through AAO layers can be performed without introducing any voids in the silicon or fumes which may be harmful to human health.
\end{abstract}

\section{Introduction}

Laser-doping is a process of incorporating dopants into a semiconductor by using a laser to scribe through a layer that contains a dopant source. Introduction of p-type dopants by laser-doping of silicon can be used to form $\mathrm{p}^{+}$silicon surface regions which can act as local emitter regions for n-type solar cells or reduce both the contact resistance at the metal/silicon interface and the dark saturation current density by shielding the minority carriers from the high surface recombination velocity at the silicon interface of p-type solar cells $[1,2]$. An approach that has been reported by many is to form aluminium-alloyed local back surface field (BSF) regions by firing screen printed aluminium paste through openings by either laser ablation or laser-doping in a rear dielectric layer [3-6]. This process can therefore potentially eliminate the multiple steps required in performing masked solid-state diffusion processes for the fabrication of silicon solar cells. Wang et al. reported the use of a poly boron solution which was spincoated on a silicon surface as a dopant source for laser-doping [2]; however it has been shown that very low laser speeds are required to achieve significant dopant incorporation from this dopant source $[1,7]$. Furthermore, fumes generated due to laser scribing through the poly boron film may present a risk to human health [8]. Dielectric layers have also been previously investigated as dopant sources for a subsequent laser-doping process, with the advantage of this process being that the dielectric layer can passivate the surface outside of the laser-doped regions [9-12].

In this paper we report the use of anodic aluminium oxide (AAO) as a dopant source for laser-doping and in particular the formation of $\mathrm{p}^{+}$doped silicon regions. These layers, which can be formed by anodising aluminium over an intervening silicon dioxide or silicon nitride dielectric layer on a silicon wafer, have been shown to improve the effective minority carrier lifetime in silicon wafers [13-15] and may also impart enhanced light trapping for thin silicon solar cells due to their nanoporous structure [16]. Being able to also provide a source of aluminium to dope the underlying silicon and form $\mathrm{p}^{+}$ regions for metal contacting purposes may make these layers useful multifunctional materials for future photovoltaic applications. In [14], residual aluminium has been reported at the valley of pyramid and this residual aluminium could also contribute as a dopant source in laser-doping process. In 
the paper, we demonstrate laser-doping of silicon using the intrinsic aluminium of an AAO layer, metallic aluminium of the residual aluminium from anodisation process, and the extrinsic impurities incorporated in the anodic oxide layer by anodising the aluminium in different electrolytes. It has been previously shown that during anodisation, ions from the electrolyte can be trapped in the AAO layer $[17,18]$. We show the incorporation of both boron and phosphorus into silicon by laser-doping through an AAO layer formed by anodising aluminium in boric acid $\left(\mathrm{H}_{3} \mathrm{BO}_{3}\right)$ and phosphoric acid $\left(\mathrm{H}_{3} \mathrm{PO}_{4}\right)$, respectively.

\section{Experimental}

Alkaline-textured Czochralski (Cz) boron-doped 1-3 $\Omega \mathrm{cm}$ silicon wafer fragments of area $\sim 16 \mathrm{~cm}^{2}$ were lightly diffused with phosphorus to an emitter sheet resistance of $\sim 100 \Omega / \square$. The residual phosphorus at the rear surface was removed by etching and $10 \mathrm{~nm}$ of $\mathrm{SiO}_{2}$ was thermally grown on both surfaces. Silicon nitride was deposited using plasma-enhanced chemical vapour deposition (Roth and Rau AK400) to a thickness of 65 and $200 \mathrm{~nm}$ on the front and rear surfaces of the wafer fragments, respectively.

An aluminium layer of thickness $600 \mathrm{~nm}$ was thermally evaporated onto the rear $\mathrm{SiN}_{x}$ surface of wafer fragments and anodised in an electrolyte comprising either (i) $0.5 \mathrm{M}$ $\mathrm{H}_{2} \mathrm{SO}_{4}$ at $25 \mathrm{~V}$; (ii) $0.5 \mathrm{M} \mathrm{H}_{2} \mathrm{SO}_{4}$ and $0.5 \mathrm{M} \mathrm{H}_{3} \mathrm{BO}_{3}$ at $25 \mathrm{~V}$; or in $0.5 \mathrm{M} \mathrm{H}_{3} \mathrm{PO}_{4}$ at $37 \mathrm{~V}$. Anodisation was performed as previously described by $\mathrm{Lu}$ et al. [13]. The anodisation rate when the electrolyte of $0.5 \mathrm{M} \mathrm{H}_{3} \mathrm{PO}_{4}$ was used is much slower than when it was anodized in $0.5 \mathrm{M} \mathrm{H}_{2} \mathrm{SO}_{4}$; therefore, the anodisation voltage for the electrolyte of $0.5 \mathrm{M} \mathrm{H}_{3} \mathrm{PO}_{4}$ was increased to maintain a similar anodisation time. A dopant layer of poly boron source (PBF1; manufactured by FILMTRONICS) was applied to the remaining wafers by spin-coating at $2000 \mathrm{rpm}$ for $30 \mathrm{~s}$ and then heating at $200^{\circ} \mathrm{C}$ for $13 \mathrm{~min}$. Regions of area $2 \mathrm{~cm} \times 2 \mathrm{~cm}$ were laser-doped through either the spin-coated layer of poly boron source or the AAO layer by scribing lines spaced $20 \mu \mathrm{m}$ apart as laser beam diameter $\left(1 / e^{2}\right)(=20 \mu \mathrm{m})$ was used by a $532 \mathrm{~nm}$ laser at a speed of $500 \mathrm{~mm} / \mathrm{s}$ and power of $15 \mathrm{~W}$.

Exemplar lines were also laser-scribed through the different dopant sources for scanning electron microscope (SEM) imaging. The secondary ion mass spectrometry (SIMS) doping profiles of the laser-doped regions were measured using a Cameca ims4f with cesium $\left(\mathrm{Cs}^{+}\right)$sputtering ions at voltage of $10 \mathrm{kV}$. Electrochemical capacitance voltage measurements were performed using a circular measuring area with a diameter of $3.57 \mathrm{~mm}$. Finally, TEM cross-sectional images of the laser-doped regions were recorded to ascertain the structural properties of the laser-doped regions.

\section{Results and Discussion}

Figure 1(a) shows the SIMS profile of a region that was laserdoped through spin-coated poly boron dopant source. The profile shows the presence of both the $\mathrm{B}^{10}$ and $\mathrm{B}^{11}$ isotopes of boron, which have a natural abundance of $20 \%$ and $80 \%$, respectively [19]. The boron from the poly boron solution is typically $\mathrm{B}^{11}$ dominant [20] which may explain why the natural abundance ratio is not strictly observed in the profile. The boron from the spin-on source was incorporated in the silicon to a depth of $12 \mu \mathrm{m}$; however the boron concentration is around $10^{19} \mathrm{~cm}^{-3}$ only in the depth of 1 to $8 \mu \mathrm{m}$.

Laser-doping offers the ability to selectively heat a region without heating the bulk of the Si wafer. Laser beams can generate sufficient heat to melt the Si. The wide range in laser power and wavelength enables patterning and melting of $\mathrm{Si}$ for different applications. Laser fluence (energy per unit area) which can be controlled by laser power and laser speed determines the thermal energy introduced into the Si; laser wavelength determines the penetration depth of the laser beam within the Si wafer. During laser-doping the silicon under the laser-irradiated region starts to melt at $1414^{\circ} \mathrm{C}$ and the molten front extends into the silicon. When the thermal energy is dissipated, recrystallisation of the molten silicon starts to occur $[1,21]$. Impurities from both the applied dopant source and the $\mathrm{SiN}_{x}$ layer are introduced into the molten region and diffuse down their concentration gradients in the melt. The process of impurity incorporation is further complicated by the existence of temperature gradients which sensitively depend on the laser energy profile and differences in the segregation coefficients of the impurities that are introduced into the molten silicon. As the laser-melted region cools the doped molten silicon recrystallises and impurities may continue to diffuse as the crystallised silicon cools further. Impurities that have larger diffusion coefficients in molten silicon are incorporated deeper in the silicon [1] with the incorporated impurity concentration being also determined to some extent by the impurity's segregation coefficient for silicon. The fact that boron was incorporated to a depth of $12 \mu \mathrm{m}$ in Figure 1(a) implies that the molten silicon region extended at least that far into the silicon wafer.

Figure 1(b) shows the SIMS profile of a region laser-doped through an AAO layer which was formed by anodising a $600 \mathrm{~nm}$ aluminium layer which had been thermally evaporated on the $\mathrm{SiN}_{x}$ surface of silicon wafer. Anodisation was performed at $25 \mathrm{~V}$ in an electrolyte comprising $0.5 \mathrm{M} \mathrm{H}_{2} \mathrm{SO}_{4}$ and $0.5 \mathrm{M} \mathrm{H}_{3} \mathrm{BO}_{3}$. Aluminium was the dominant dopant introduced into the silicon during the laser-doping process, penetrating to a depth of $11 \mu \mathrm{m}$, whereas the boron was only incorporated to a depth of $1 \mu \mathrm{m}$. Note, due to the much lower boron concentration in this profile, only a $\mathrm{B}^{11}$ signal was detected by SIMS. The difference in the incorporation depth of the aluminium and boron in Figure 1(b) cannot be fully accounted for on the basis of their different diffusion coefficients in molten silicon (aluminium: $7.0 \pm 3.1 \times 10^{-4} \mathrm{~cm}^{2} \mathrm{~s}^{-1}$ compared to boron: $2.4 \pm 0.7 \times 10^{-4} \mathrm{~cm}^{2} \mathrm{~s}^{-1}$ [22]). Kuhlmann et al. [23] report an enhancement in the solid-state diffusion of aluminium in the presence of boron by a factor of three. It was proposed that this enhancement was due to a supersaturation of self-interstitials caused by the presence of boron. It is interesting to speculate that similar diffusion-enhancement processes may exist for diffusion in molten silicon during laser-doping processes.

Dopant incorporation into silicon during laser-doping may also be affected by the segregation coefficient of the 


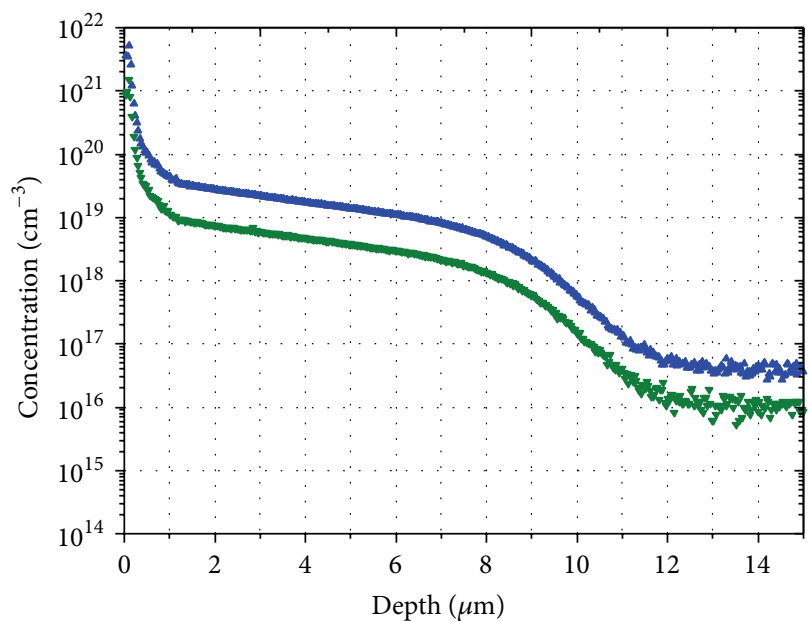

$\triangle \mathrm{B}^{11}$

- $\mathrm{B}^{10}$

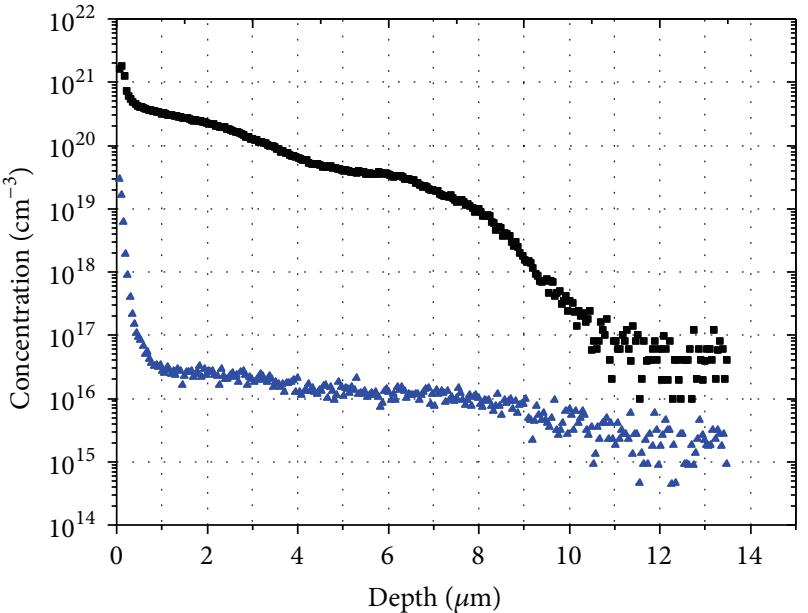

- $\mathrm{Al}$

- $\mathrm{B}^{11}$

(a)

(b)

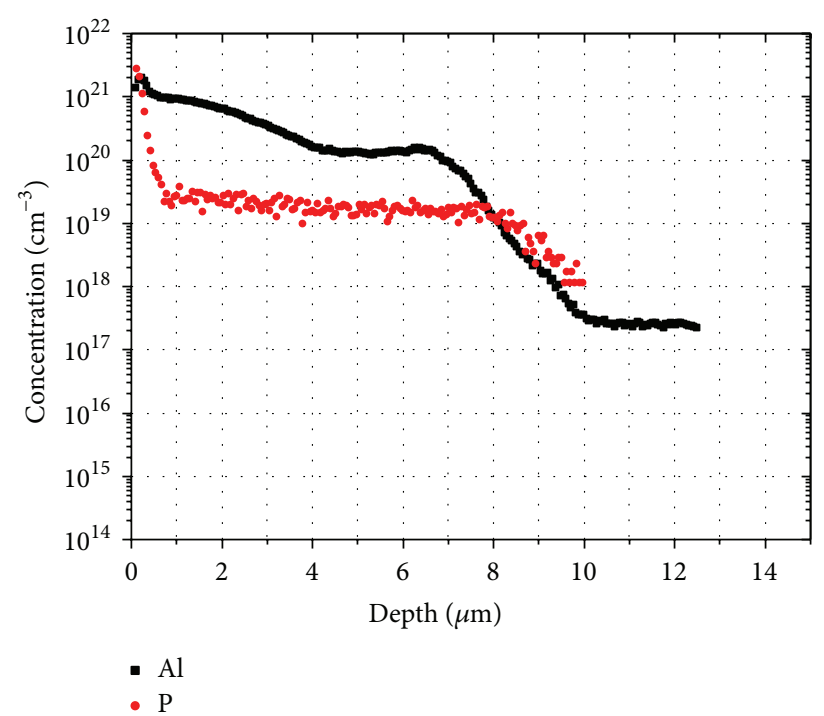

(c)

FIGURE 1: SIMS profiles of $4 \mathrm{~cm}^{2}$ square laser-doped regions that were formed by scribing laser lines $20 \mu \mathrm{m}$ apart using a $532 \mathrm{~nm}$ laser and a speed of $500 \mathrm{~mm} / \mathrm{s}$ and laser power of $15 \mathrm{~W}$. In (a) the laser lines were scribed through a spin-coated boron dopant layer. The profiles of detected boron $10(\boldsymbol{\nabla})$ and boron $11(\mathbf{\Lambda})$ are shown. In (b) laser-doping was performed through an AAO layer that was formed by anodising aluminium at $25 \mathrm{~V}$ in an electrolyte comprising $0.5 \mathrm{M}$ of $\mathrm{H}_{2} \mathrm{SO}_{4}$ and $0.5 \mathrm{M}$ of $\mathrm{H}_{3} \mathrm{BO}_{3}$. The profiles show detected boron 11 ( $\mathbf{\Delta}$ ) and aluminium (匹). In (c) laser-doping was performed through an AAO layer formed by anodising aluminium in $0.5 \mathrm{M} \mathrm{H}_{3} \mathrm{PO}_{4}$ at $37 \mathrm{~V}$. The profile shows detected phosphorus $(\bullet)$ and aluminium $(\boldsymbol{\square})$.

diffusing impurities. The segregation coefficient of boron in silicon at thermal equilibrium is 0.8 which is considerably larger than the corresponding value of 0.002 for aluminium [24]. If thermal equilibrium was approached during the laserdoping process, it would be expected that significantly more boron than aluminium would be incorporated in the recrystallised silicon. The fact that this was not observed suggests that laser-doping is not an equilibrium process even at the relatively slow processing speeds used in this study, and boron incorporation in the silicon was limited by its diffusion in the molten silicon. The effects of segregation between liquid and solid were considered to be relatively minor in the laser melting/recrystallization process, where large thermal and concentration gradients evolve over a rapid time frame, and they would be expected to vary during the recrystallization process. As has been previously noted, thermodynamic equilibrium segregation coefficients are only strictly correct for slow silicon growth rates in well stirred melts [25]. It could be argued that the higher surface concentration of boron in Figure 1(a) compared to aluminium in Figure 1(b) may be 
due to boron's higher segregation coefficient; however this is difficult to substantiate in the absence of accurate data for the effective dopant concentration at the surface prior to laserdoping as the properties of the poly boron film and AAO layer are so different.

For comparison, Figure 1(c) shows the SIMS profile of a similar region laser-doped through an AAO layer that was formed by anodising a $600 \mathrm{~nm}$ aluminium layer at $37 \mathrm{~V}$ in $0.5 \mathrm{M} \mathrm{H}_{3} \mathrm{PO}_{4}$. Although aluminium is incorporated in the silicon to approximately the same depth as the sample which was laser-doped through the AAO layer formed by aluminium anodisation in $0.5 \mathrm{M} \mathrm{H}_{2} \mathrm{SO}_{4}$ and $0.5 \mathrm{M} \mathrm{H}_{3} \mathrm{BO}_{3}$ (see Figure 1(b)), its concentration is higher in the doped region indicating increased aluminium incorporation in silicon in the presence of phosphorus. Nagel et al. reported that solidstate diffusion of aluminium was enhanced in the presence of phosphorus due to field-assisted diffusion arising from aluminium diffusing as negatively charged ion and phosphorus diffusing as a positive ion-vacancy pair [23, 26]. Furthermore, the aluminium profile in Figure 1(c) has a local minimum at $5 \mu \mathrm{m}$. This is similar to the aluminium solid-state diffusion profile (in the presence of phosphorus) reported by Kuhlmann et al. [23] that can be explained by the up-hill migration of aluminium ions towards the surface caused by the electric field of the phosphorus profile.

A significantly higher level of phosphorus incorporation was observed in Figure 1(c) compared to the boron incorporation in Figure 1(b). This could be partly due to the higher anodisation voltage that was required for anodisation in the $0.5 \mathrm{M} \mathrm{H}_{3} \mathrm{PO}_{4}$ electrolyte, as more impurities from the electrolyte may have become incorporated into the anodic film at higher voltages [17]. The concentration of boron and phosphorus incorporated within aluminium wires, evaporated aluminium film, and AAO was measured by dissolving aluminium wires, evaporated aluminium film, and AAO film

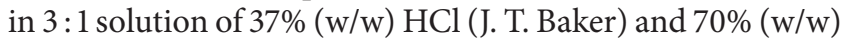
$\mathrm{HNO}_{3}$ (J. T. Baker) and analysing the solution by inductively coupled plasma-mass spectrometry (ICP-MS). The concentration of phosphorus within the AAO layer is more than 7 times larger than that of boron (2116 ppm to $15795 \mathrm{ppm}$ ) as a result of these particular anodisation conditions, which might result in a difference in surface concentration between boron and phosphorus. However, the increased phosphorus incorporation in silicon compared to boron may also be due to the larger diffusion coefficient of phosphorus $(5.1 \pm 1.7 \times$ $10^{-4} \mathrm{~cm}^{2} \mathrm{~s}^{-1}$ ) [22] compared to boron in molten silicon.

The difference in the incorporation depth of the aluminium and boron in Figure 2 was assumed to be at least in part due to the larger diffusion coefficient of aluminium (7.0 \pm $\left.3.1 \times 10^{-4} \mathrm{~cm}^{2} \mathrm{~s}^{-1}\right)$ compared to boron $\left(2.4 \pm 0.7 \times 10^{-4} \mathrm{~cm}^{2} \mathrm{~s}^{-1}\right)$ in molten silicon [22]. To examine the role of the differing diffusion coefficients in molten $\mathrm{Si}$, dopant profiles were calculated assuming a Gaussian diffusion profile, a surface dopant concentration of $10^{21} \mathrm{~cm}^{-3}$, and a diffusion time of $30 \mu \mathrm{s}$ for aluminium ( $\left.\mathbf{\square} D=7.0 \times 10^{-4} \mathrm{~cm}^{2} \mathrm{~s}^{-1}\right), \mathrm{B}(\mathbf{\Delta} ; D=2.4 \times$ $\left.10^{-4} \mathrm{~cm}^{2} \mathrm{~s}^{-1}\right)$, and $\mathrm{P}\left(\boldsymbol{\bullet} D=5.1 \times 10^{-4} \mathrm{~cm}^{2} \mathrm{~s}^{-1}\right)$ in Figure 2 [22]. The diffusion time was selected in order to match the penetration depth of the aluminium. It is clear from Figure 1

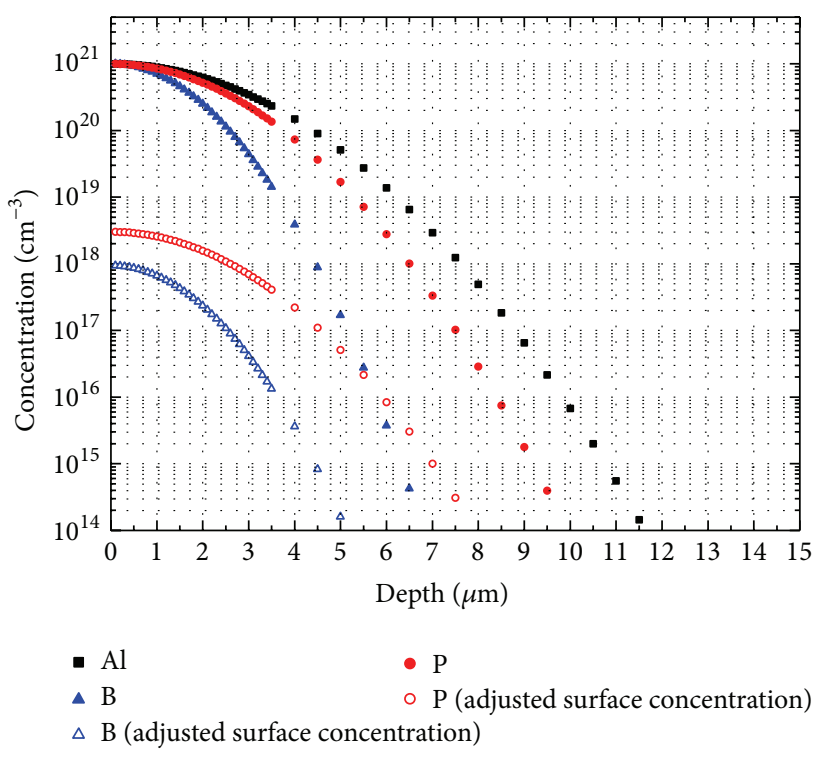

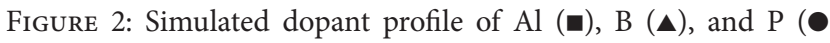
assuming a Gaussian diffusion profile, a surface concentration of $10^{21} \mathrm{~cm}^{-3}$, and a diffusion time of $30 \mu \mathrm{s}$. The open triangles $(\triangle)$ and circles $(\mathrm{O})$ represent the simulated doping profile of $\mathrm{B}$ and $\mathrm{P}$ when the surface concentration was adjusted according to concentration ratio with $\mathrm{AAO}$ layer.

that the measured dopant profiles cannot be fully explained by differences in the diffusion coefficients in molten silicon. Even when the surface concentration of boron and phosphorus was adjusted to the lower concentration implied by the ratio (open symbols in Figure 2), the modelling still does not explain the 3 order concentration differences between boron and phosphorus as shown in Figure 1. In other words, the difference in the incorporation depth of the $\mathrm{Al}$, phosphorus, and boron in Figure 2 cannot be fully accounted for on the basis of their different diffusion coefficients in molten silicon. However, the laser-doped lines might slightly overlap to each other to create a laser-doped square for SIMS measurement. With this laser-doping condition, it is highly possible that the silicon remains in a molten state longer than simulated time used in Figure 2. The solidification time of the molten silicon can be very different at $5 \mu \mathrm{m}$ and the surface.

Although Figure 1 demonstrates that both intrinsic (e.g., aluminium) and extrinsic (e.g., boron and phosphorus) impurities in AAO layers can be incorporated into silicon, device performance requires that the introduced dopants are also electrically active. Figure 3 shows the p-type dopant profile, determined using electrochemical capacitance voltage (ECV) measurements, for regions laser-doped through the poly boron spin-on dopant source and through an AAO layer formed by anodising aluminium at $25 \mathrm{~V}$ in an electrolyte comprising $0.5 \mathrm{M} \mathrm{H}_{2} \mathrm{SO}_{4}$ and $0.5 \mathrm{M} \mathrm{H}_{3} \mathrm{BO}_{3}$. Although the (electrical) junction depth exceeded $10 \mu \mathrm{m}$ in both cases, laserdoping through the AAO layer resulted in a higher dopant concentration in the $\mathrm{p}^{+}$region than the equivalent process using the poly boron spin-on source. The electrically active $\mathrm{p}-$ type dopant concentration exceeded $10^{20} \mathrm{~cm}^{-3}$ over the first $4 \mu \mathrm{m}$ of the region formed by doping through the AAO layer, 


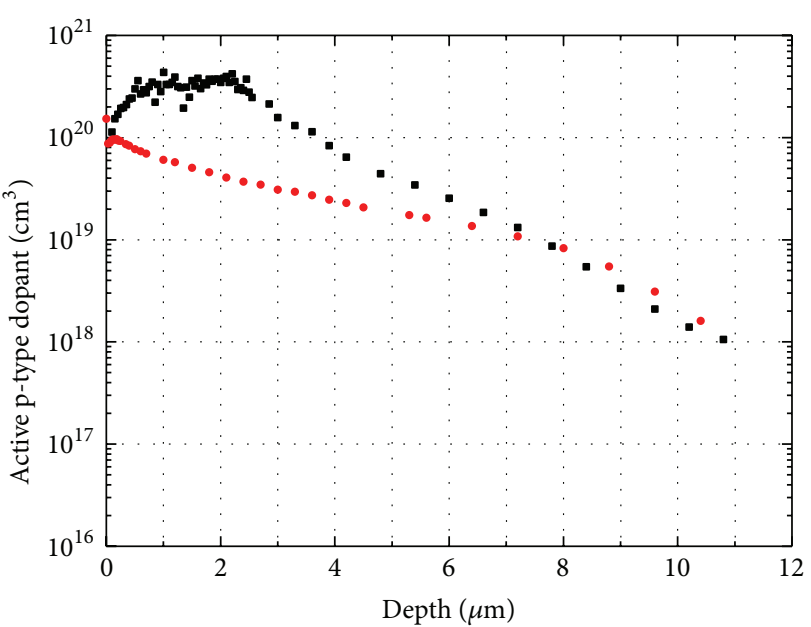

FIGURE 3: ECV profiles showing electrically active p-type dopant concentration in a $4 \mathrm{~cm}^{2}$ region which was laser-doped through (a) spin-coated poly boron dopant $\operatorname{source}(\bullet)$ and (b) an AAO layer formed by anodising aluminium at $25 \mathrm{~V}$ in an electrolyte comprising $0.5 \mathrm{M}$ of $\mathrm{H}_{2} \mathrm{SO}_{4}$ and $0.5 \mathrm{M}$ of $\mathrm{H}_{3} \mathrm{BO}_{3}(\mathbf{\square})$. Both regions were formed by laser-doping a sequence of lines which were spaced $20 \mu \mathrm{m}$ using a $532 \mathrm{~nm}$ laser and a speed of $500 \mathrm{~mm} / \mathrm{s}$ and laser power of $15 \mathrm{~W}$.

whereas this dopant concentration was only achieved over the first $300 \mathrm{~nm}$ of the region laser-doped through the poly boron spin-on source. As discussed previously, the greater amount of p-type dopant is being incorporated through melting results from laser-doping through the AAO. This is primarily due to aluminium's larger diffusion coefficient. Consequently, when laser-doping uses the same laser speed and power, more aluminum can diffuse into the silicon and diffuses further from the surface than the introduced boron. Although the laser-doping conditions were identical for both samples, the thermal energy absorbed by the silicon would have been different because the reflectance of the AAO layer at $532 \mathrm{~nm}$ was much higher than measured for $200 \mathrm{~nm}$ of $\mathrm{SiN}_{x}$, consequently less laser power would have been less into the AAOcoated silicon.

Figure 4 shows SEM top-view images of lines laser-doped through the poly boron spin-on source (Figure 4(a)), through an AAO layer formed by anodising aluminium in $0.5 \mathrm{M}$ $\mathrm{H}_{2} \mathrm{SO}_{4}$ (Figure 4(b)), and through an AAO layer formed by anodising aluminium at $25 \mathrm{~V}$ in an electrolyte comprising $0.5 \mathrm{M} \mathrm{H}_{2} \mathrm{SO}_{4}$ and $0.5 \mathrm{M} \mathrm{H}_{3} \mathrm{BO}_{3}$ (Figure 4(c)). All the lines were laser-doped using a laser speed of $500 \mathrm{~mm} / \mathrm{s}$ and power of $15 \mathrm{~W}$. Large "holes" are evident along the line laser-doped through the poly boron spin-on source, whereas the lines which were laser-doped through AAO layers were smooth and free of holes. Sugianto also observed "holes" after laserdoping through the same poly boron dopant source and attributed them to trapped gas impurities which vent at the surface. She showed that the size and density of holes decreased when the laser scan speed was increased supporting the theory that reduced impurity incorporation occurs at faster laser speeds [21]. It is also notable that the line that was laser-doped through the poly boron spin-on source appears raised above the textured silicon nitride surface. This is quite different morphologically from the lines laser-doped through AAO layers where the level of the line lies below the surface of the dielectric layer.

Given the surface manifestation of laser-doping defects in Figure 5(a), transmission electron microscopy (TEM) crosssectional images and energy dispersive X-ray (EDX) mapping images were used to investigate whether further evidence of gas generation or other defects could be detected below the surface of the laser-doped regions. Figure 5 shows TEM and corresponding EDX images of regions which were laserdoped through boron spin-on dopant source (Figures 5(a) and $5(\mathrm{c}))$ and through an AAO layer formed by anodisation of aluminium in $0.5 \mathrm{M} \mathrm{H}_{2} \mathrm{SO}_{4}$ at $25 \mathrm{~V}$ (Figures 5(b) and 5(d)). Both lines were formed using a laser speed of $500 \mathrm{~mm} / \mathrm{s}$ and power of $15 \mathrm{~W}$. A large void, which was $\sim 2 \mu \mathrm{m}$ in length, is evident in Figure 5(a) confirming that voids are also formed in the laser-doped silicon and not just on the surface. If these voids are fully contained within the laser-doped $\mathrm{p}^{+}$silicon, then their electrical impact will be minor as the electron concentration is low in these regions and consequently recombination associated with the defects will be minimal. However if the voids result in crystal stress, then it is possible that crystal defects (e.g., dislocations) may be propagated into the bulk of the wafer. In comparison the laser-doped silicon region in Figure 4(b) is free of voids and crystal structure defects. The AAO layer is only partially ablated by the laserscribing and the residue of the layer retains a network of pores.

The EDX image in Figure 5(c) depicts the laser-doped region in Figure 5(a) and indicates low levels of boron (blue) incorporation in the laser-doped silicon region. Boron is difficult to detect using EDX when the window of the detector crystal is composed of beryllium because the X-ray signal is attenuated if the element is lighter than sodium. Since this was the case for these analyses, boron identification in the EDX maps in Figure 5 may not be reliable. The EDX image in Figure 5(d) depicts the laser-doped region in Figure 5(b). Large regions of aluminium (red) can be seen in the silicon showing that the dopant has not been uniformly incorporated into the silicon lattice. The nonuniform aluminium incorporation may be accentuated by the method of scribing multiple adjacent laser lines to form a square region for analysis; however it is interesting to note the boron-doping in Figure 5(c) appeared more uniform.

In both samples a layer rich in oxygen forms at the surface of the laser-doped region. In the case of the sample that was laser-doped through the AAO layer the layer appears of uniform thickness and $\sim 50 \mathrm{~nm}$ in thickness. It may comprise residual oxide from the dielectric stack that has become segregated to the surface of the laser-doped region or it may also form due to molten silicon reacting with oxygen from the ambient. The ramifications of this are that before metal contacting can be achieved deglazing will be necessary.

\section{Conclusions}

This paper demonstrates that aluminium can be introduced into silicon to form localised $\mathrm{p}^{+}$surface regions by laserdoping through an AAO layer formed on the silicon surface. 


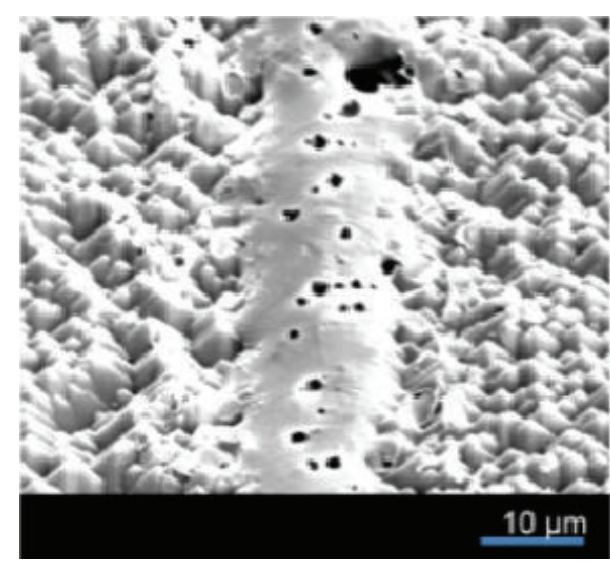

(a)

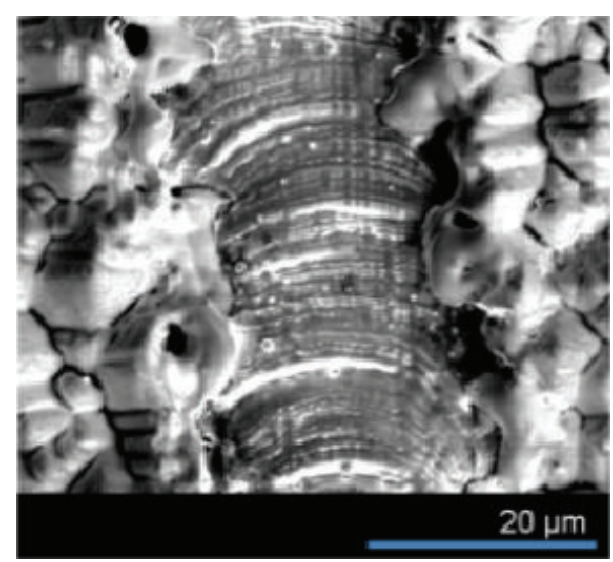

(b)

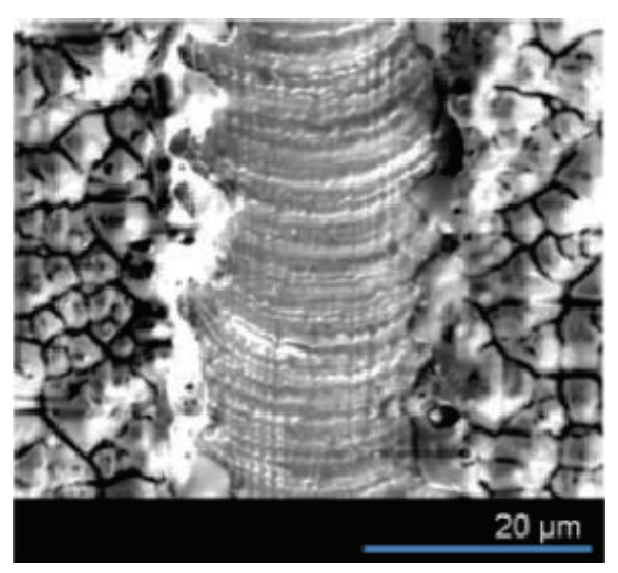

(c)

FIGURE 4: Scanning electron microscope top-view images of (a) a line laser-doped through the boron spin-on dopant source; (b) a line laserdoped through an AAO layer which was formed by anodisation of aluminium in $0.5 \mathrm{M} \mathrm{H}_{2} \mathrm{SO}_{4}$; and (c) a line laser-doped through an AAO layer which was formed by anodisation of aluminium at $25 \mathrm{~V}$ in an electrolyte comprising $0.5 \mathrm{M} \mathrm{H}_{2} \mathrm{SO}_{4}$ and $0.5 \mathrm{M}$ of $\mathrm{H}_{3} \mathrm{BO}_{3}$. All the lines were scribed by a $532 \mathrm{~nm}$ laser using a speed of $500 \mathrm{~mm} / \mathrm{s}$ and power of $15 \mathrm{~W}$.

The introduced aluminium can penetrate the silicon at least $10 \mu \mathrm{m}$ from the surface with the laser-doping conditions used, and unlike laser-doping through a poly boron spin-coated layer the concentration of electrically active p-type dopant exceeds $1 \times 10^{20} \mathrm{~cm}^{-3}$ for the first $6-7 \mu \mathrm{m}$ of the $\mathrm{p}^{+}$region. A heavy doped $\mathrm{p}^{+}$region can be formed by laser scribed through boron-doped AAO which was formed by anodizing aluminium in the mixture of $0.5 \mathrm{M} \mathrm{H}_{2} \mathrm{SO}_{4}$ and $0.5 \mathrm{M} \mathrm{H}_{3} \mathrm{BO}_{3}$ at $25 \mathrm{~V}$. The higher dopant concentration in the $\mathrm{p}^{+}$regions, which occurs most likely because aluminium diffuses $\sim$ three times faster than boron in molten silicon, can result in more effective shielding of minority carriers from the silicon surface and hence improved device performance.

The anodic oxide layers can be doped with other impurities (e.g., boron and phosphorus) by anodising aluminium in electrolytes containing the extrinsic impurities in ionic form. The ions become trapped in the formed AAO layer during anodisation, therefore enabling the impurity to be introduced into the silicon, with aluminium, during laser-doping. This codoping process can be used to create very heavily doped surface layers which can reduce contact resistance on metallisation, whilst the deeper doping achieved by the intrinsic aluminium may act more to shield the surface from minority carriers.

It is concluded that laser-doping through AAO layers may be a useful way of forming localised $\mathrm{p}^{+}$regions in $\mathrm{p}$-type silicon solar cells. The process can result in more heavily doped $\mathrm{p}^{+}$regions than the previously described method of laserdoping through a poly boron source. Furthermore, it can be performed without introducing defects in the silicon or fumes which may be harmful to human health. If AAO layers can be used in this way to create local $\mathrm{p}^{+}$regions, whilst also enabling high carrier lifetimes and therefore cell voltages, they may represent a multifunctional material for silicon solar cell passivation and contact formation.

\section{Disclaimer}

The views expressed herein are not necessarily the views of the Australian Government, and the Australian Government 


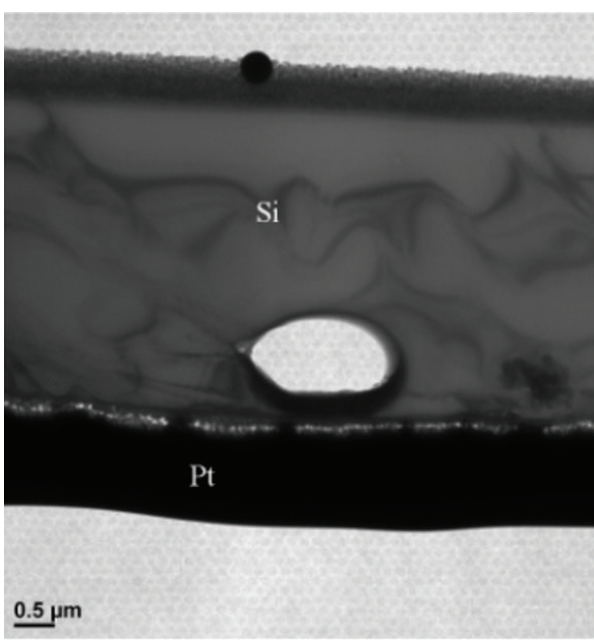

(a)

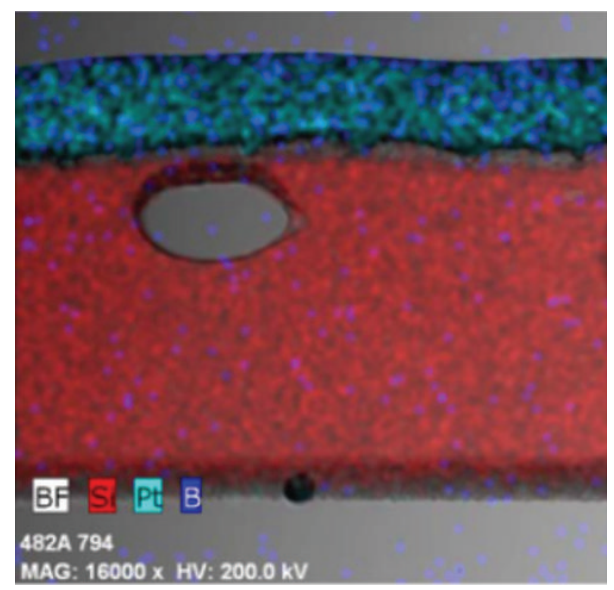

(c)

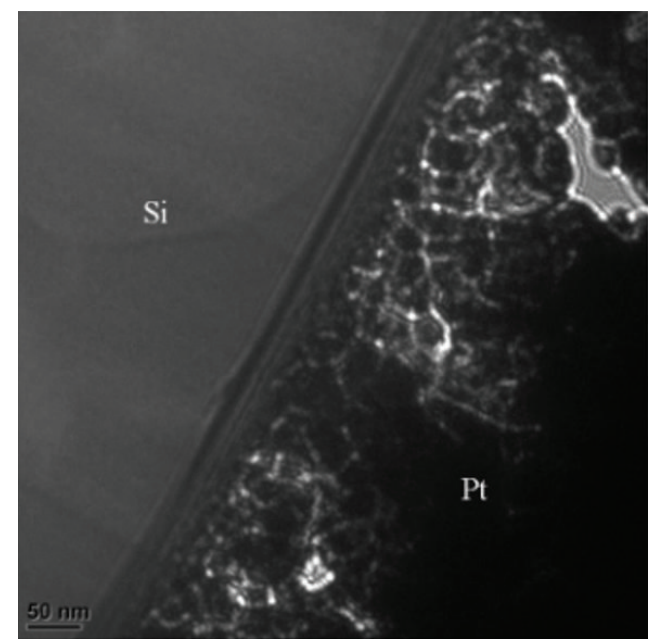

(b)

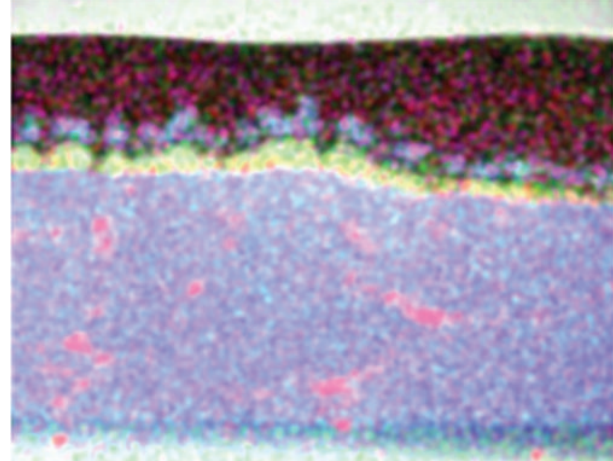

BF Al S Au D

(d)

FIGURE 5: Transmission electron microscopy cross-sectional images of regions: (a) laser-doped through a spin-coated boron dopant layer and (b) laser-doped through an AAO layer formed by aluminium anodisation at $25 \mathrm{~V}$ in $0.5 \mathrm{M} \mathrm{H}_{2} \mathrm{SO}_{4}$. The laser-doping was performed using a $532 \mathrm{~nm}$ laser and a speed of $500 \mathrm{~mm} / \mathrm{s}$ and operation power of $15 \mathrm{~W}$. (c) and (d) show EDX mapping images of (a) and (b), respectively. Note that the orientation of (c) and (d) is changed from (a) and (b).

does not accept responsibility for any information or advice contained herein.

\section{Conflict of Interests}

The authors declare that there is no conflict of interests regarding the publication of this paper.

\section{Acknowledgment}

This program has been supported by the Australian Government through the Australian Renewable Energy Agency (ARENA). The Australian Government, through ARENA, is supporting Australian research and development in solar photovoltaic and solar thermal technologies to help solar power become cost competitive with other energy sources.

\section{References}

[1] B. Hallam, C. Chan, A. Sugianto, and S. Wenham, "Deep junction laser doping for contacting buried layers in silicon solar cells," Solar Energy Materials and Solar Cells, vol. 113, pp. 124134, 2013.

[2] Z. Wang, P. Han, H. Lu et al., "Advanced PERC and PERL production cells with $20.3 \%$ record efficiency for standard commercial p-type silicon wafers," Progress in Photovoltaics: Research and Applications, vol. 20, no. 3, pp. 260-268, 2012.

[3] S. W. Glunz, J. Benick, D. Biro et al., "n-Type silicon-enabling efficiencies $>20 \%$ in industrial production," in Proceedings of the 35th IEEE Photovoltaic Specialists Conference (PVSC '10), pp. 50-56, IEEE, Honolulu, Hawaii, USA, June 2010.

[4] A. Metz, D. Adler, S. Bagus et al., "Industrial high performance crystalline silicon solar cells and modules based on rear surface passivation technology," Solar Energy Materials and Solar Cells, vol. 120, pp. 417-425, 2014. 
[5] B. Tjahjono, M. J. Yang, V. Wu, J. Ting, J. Shen, O. Tan et al., "Optimizing CELCO cell technology in one year of mass production," in Procedding of 28th European Photovoltaic Solar Energy Conference and Exhibition, Paris, France, September 2013.

[6] L. Tous, R. Russell, M. Debucquoy et al., "Power-loss analysis of advanced PERC cells reaching 20.5\% energy conversion efficiency," Energy Procedia, vol. 38, pp. 467-473, 2013.

[7] A. Sugianto, B. Hallam, X. Bai et al., "Over 20\%-efficient laserdoped passivated rear contact solar cells on industrial-sized commercial grade p-type CZ wafers," in Proceedings of the 27th European Photovoltaic Solar Energy Conference and Exhibition, pp. 700-705, Frankfurt, Germany, 2012.

[8] (ATSDR), Toxic Substances Portal for Boron, ATSDR, 2010, http://www.atsdr.cdc.gov/phs/phs.asp?id=451\&tid=80.

[9] B. Paviet-Salomon, S. Gall, R. Monna et al., "Laser doping using phosphorus-doped silicon nitrides," Energy Procedia, vol. 8, pp. 700-705, 2011.

[10] D. Suwito, U. Jäger, J. Benick, S. Janz, M. Hermle, and S. W. Glunz, "Industrially feasible rear passivation and contacting scheme for high-efficiency n-type solar cells yielding a Voc of 700 mV," IEEE Transactions on Electron Devices, vol. 57, no. 8, pp. 2032-2036, 2010.

[11] P. Ortega, I. Martín, G. Lopez et al., "P-type c-Si solar cells based on rear side laser processing of $\mathrm{Al}_{2} \mathrm{O}_{3} / \mathrm{SiC} \mathrm{x}$ stacks," Solar Energy Materials and Solar Cells, vol. 106, pp. 80-83, 2012.

[12] I. Martín, P. Ortega, M. Colina, A. Orpella, G. López, and R. Alcubilla, "Laser processing of $\mathrm{Al}_{2} \mathrm{O}_{3} / \mathrm{a}-\mathrm{SiC}_{\mathrm{x}}: \mathrm{H}$ stacks: a feasible solution for the rear surface of high-efficiency p-type c-Si solar cells," Progress in Photovoltaics: Research and Applications, vol. 21, no. 5, pp. 1171-1175, 2013.

[13] P. H. Lu, K. Wang, Z. Lu, A. J. Lennon, and S. R. Wenham, "Anodic aluminum oxide passivation for silicon solar cells," IEEE Journal of Photovoltaics, vol. 3, no. 1, pp. 143-151, 2013.

[14] Z. Lu, P. H. Lu, J. Cui, K. Wang, and A. Lennon, "Selfpatterned localized metal contacts for silicon solar cells," Journal of Materials Research, vol. 28, no. 15, pp. 1984-1994, 2013.

[15] J. Cui, X. Wang, and A. Lennon, "Light-induced anodisation of aluminium for rear surface passivation of silicon solar cells," in Proceedings of the 28th European PV Solar Energy Conference and Exhibition, Paris, France, 2013.

[16] Y. Li, Z. Lu, and A. J. Lennon, "Optical modeling of anodic aluminum oxide for light-trapping in silicon solar cells," in Proceedings of the Solar Conference, Melbourne, Australia, 2012.

[17] J. Lambert, C. Guthmann, C. Ortega, and M. Saint-Jean, "Permanent polarization and charge injection in thin anodic alumina layers studied by electrostatic force microscopy," Journal of Applied Physics, vol. 91, no. 11, pp. 9161-9169, 2002.

[18] L. Zhang, G. E. Thompson, M. Curioni, and P. Skeldon, "Anodizing of aluminium in sulfuric acid/boric acid mixed electrolyte," Journal of the Electrochemical Society, vol. 160, no. 4, pp. C179-C184, 2013.

[19] P. G. Bentley and A. N. Hamer, "Boron-10 abundance in nature," Nature, vol. 182, no. 4643, pp. 1156-1157, 1958.

[20] R. E. Zeebe, "Stable boron isotope fractionation between dissolved $\mathrm{B}(\mathrm{OH})_{3}$ and $\mathrm{B}(\mathrm{OH})_{4}^{-}$, Geochimica et Cosmochimica Acta, vol. 69, no. 11, pp. 2753-2766, 2005.

[21] A. Sugianto, Development of commerical high-efficiency silicon solar cells using selective emitters and passivated rear contacts [Ph.D. thesis], School of Photovoltaics and Renewable Energy Engineering, University of New South Wales, Sydney, Australia, 2011.
[22] H. Kodera, "Diffusion coefficients of impurities in silicon melt," Japanese Journal of Applied Physics, vol. 2, no. 4, pp. 212-219, 1963.

[23] U. Kuhlmann, D. Nagel, and R. Sittig, "Short-time diffusion of aluminium in silicon and co-diffusion with phosphorus and boron," Defect and Diffusion Forum, vol. 143-147, pp. 1009-1014, 1997.

[24] B. R. Bathey and M. C. Cretella, "Solar-grade silicon," Journal of Materials Science, vol. 17, no. 11, pp. 3077-3096, 1982.

[25] P. S. Ravishankar, L. P. Hunt, and R. W. Francis, "Effective segregation coefficient of boron in silicon ingots grown by the czochralski and bridgman techniques," Journal of the Electrochemical Society, vol. 131, no. 4, pp. 872-874, 1984.

[26] D. Nagel, C. Frohne, and R. Sittig, "Rapid thermal diffusion of aluminum in silicon and its interaction with phosphorus," Applied Physics A: Materials Science \& Processing, vol. 60, no. 1, pp. 61-65, 1995. 

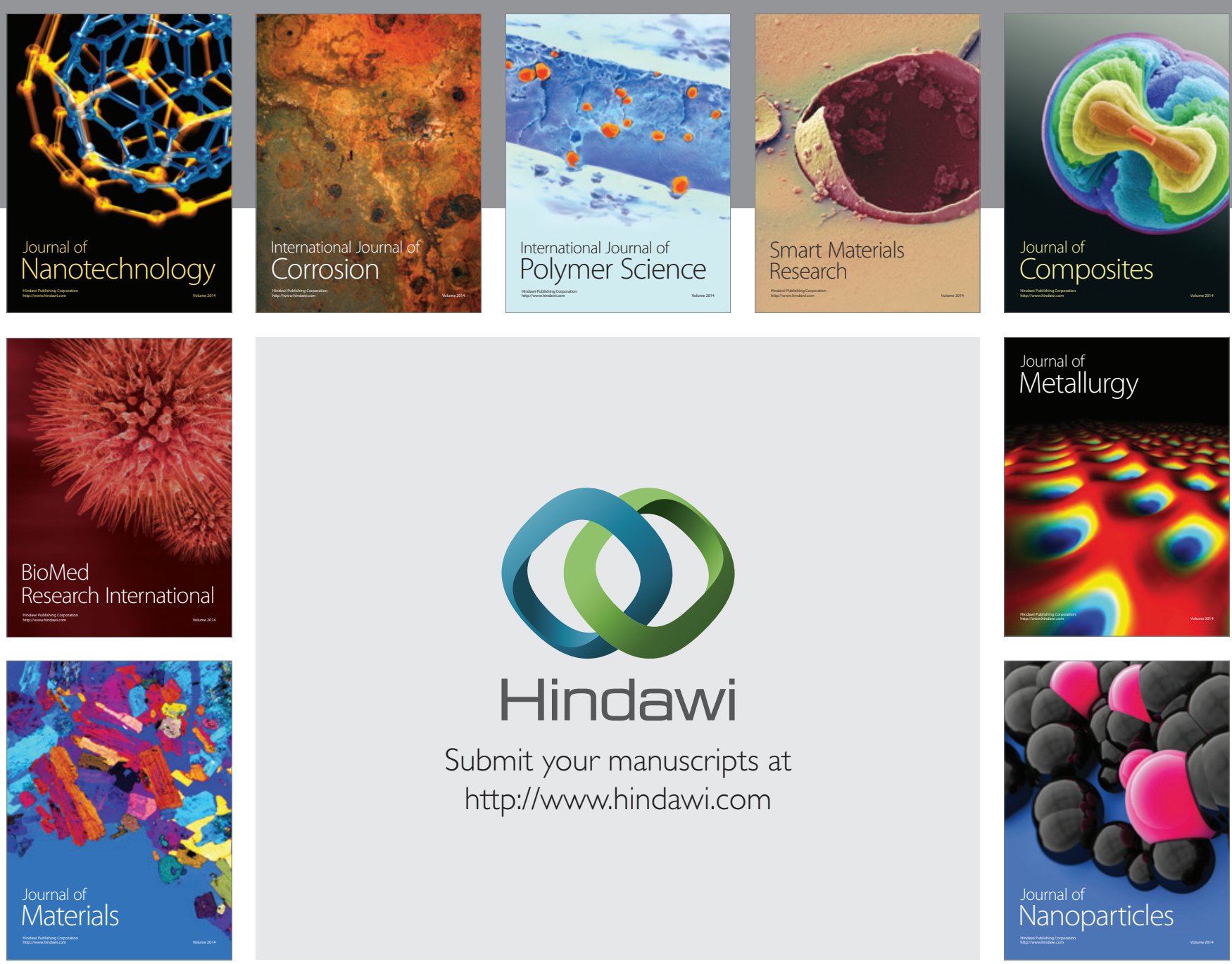

Submit your manuscripts at http://www.hindawi.com
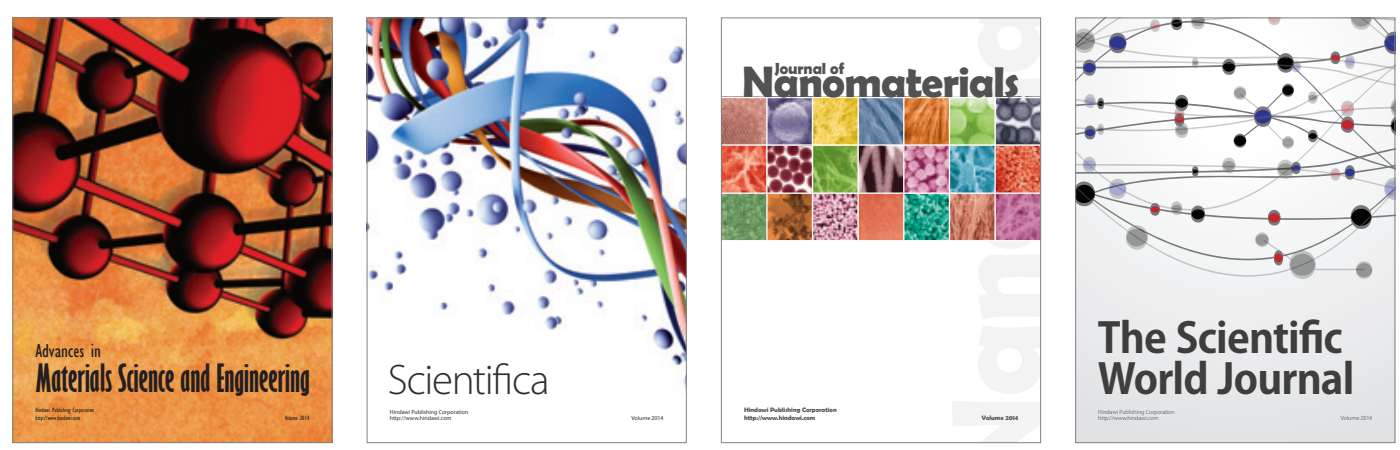

\section{The Scientific World Journal}
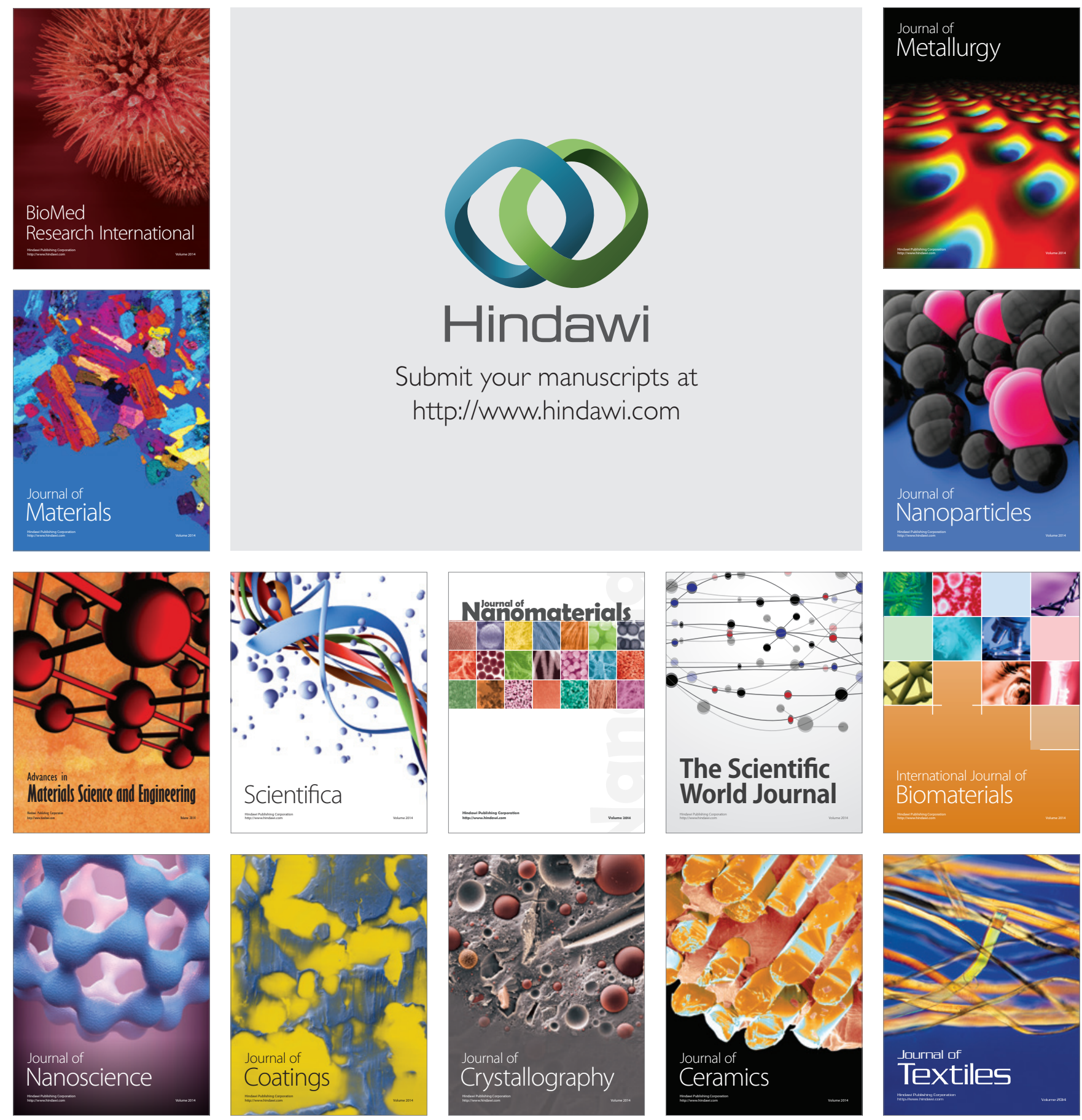